\title{
A efetividade do Direito Constitucional Palestino
}

\author{
The effectiveness of Constitutional Law In Palestine
}

\author{
Rosilandy Carina CÂNDido Lapa \\ Universidade Católica de Santos
}

Raphael Feitosa Fisori

Universidade Católica de Santos

\begin{abstract}
Resumo Propomos a partir deste artigo uma análise acerca da evolução do reconhecimento do Estado Palestino, sua organização e constituição, com o intuito de identificar a sua efetividade nos dois territórios: Cisjordânia e Faixa de Gaza, bem como, a sua relevância para os atores regionais e internacionais. Primeiro, observamos as discussões e argumentos realizados no âmbito das Nações Unidas para compreender o interesse dos Estados nas propostas de divisão territorial. Em seguida, há uma análise a respeito da importância da constituição para legitimar o Estado conforme o modelo Vestfaliano, que considera fundamental uma estrutura de governo. Por fim, comparamos os artigos das constituições da Palestina e Israel para verificar as inconsistências provenientes dos conflitos políticos sobre o território. Em nossas considerações, avaliamos que a influência de atores secundários que possuem relações comerciais com Israel, bem como, as divergências político-religiosas, dificultam o diálogo acerca do respeito às fronteiras palestinas.
\end{abstract}

Palavras-chave: Israel. Palestina. Constituição. Jerusalém.

\begin{abstract}
We propose from this article an analysis of the evolution of the recognition of the Palestinian State, its organization and constitution, in order to identify its effectiveness in the two territories: the West Bank and the Gaza Strip, as well, as its relevance for regional and international actors. First, we analyze the discussions and arguments made within the United Nations to understand the interest of States in the proposals for territorial division. Next, there is an analysis of the importance of the constitution to legitimize the state
\end{abstract}


according to the Westphalian model, which considers structured government as a core characteristic. Finally, we compare the articles of the constitutions of Palestine and Israel to verify the inconsistencies arising from political conflicts over the territory. In our considerations, we consider that the influence of secondary actors who have commercial relations with Israel, as well as political and religious differences, make it difficult to dialogue about respect for Palestinian borders.

Key-words: Israel. West Bank. Constitution. Jerusalem.

\section{INTRODUÇÃo}

O Direito Constitucional Palestino é um tema pouco explorado na literatura jurídica. Notadamente, o reconhecimento do Estado Palestino obtém maior atenção da comunidade internacional devido à complexidade das negociações, que envolvem atores com interesses próprios, influenciando diretamente qualquer avanço ou retrocesso. Ao longo dos 69 anos entre a divisão territorial promovida pela Organização das Nações Unidas (ONU, 1948), e os dias atuais, árabes palestinos e israelenses conflitam seus interesses sem previsão de resolução, e cada povo buscou maneiras de afirmar a sua legitimidade e posicionamento. Os árabes palestinos não reconheceram o Estado de Israel e a divisão de território, enquanto os israelenses utilizaram ferramentas para reduzir o território palestino árabe por intermédio de acampamentos financiados pelo governo, bem como, a expulsão de palestinos que possuíam propriedades em Israel.

O território palestino restringe-se atualmente à região da Cisjordânia e Faixa de Gaza. Entre 1994 e 2005, ambos os territórios foram controlados pela Autoridade Nacional Palestina, que surgiu a partir dos acordos de Oslo (1993). Em 2002, a Constituição da Palestina foi promulgada e as negociações com o Estado de Israel para a completa retirada de colonos da Faixa de Gaza avançaram. Contudo, no ano de 2006 o partido Hamas venceu as eleições na Faixa de Gaza, em oposição ao Fatah, que controlava a Cisjordânia, enfraquecendo as relações com Israel que considera o Hamas um grupo terrorista. Como resultado, o Presidente da Autoridade Nacional Palestina, Mahmoud Abbas, tentou 
destituir o primeiro-ministro eleito, gerando conflitos entre os grupos. Israel iniciou investidas em Gaza, no ano de 2014, sob o pretexto da eliminação de células terroristas, resultando em 1.462 mortes de civis e 100 mil pessoas desalojadas, segundo relatório das Nações Unidas. ${ }^{1}$

Os primórdios da Constituição moderna remontam da Déclaration des droits de l'homme et du citoyen, de 1789 e da Bill of rights, de 1689, ambas prevendo a liberdade e igualdade, além dos direitos naturais e imprescritíveis. Em aditivo, as declarações foram aprimoradas com o avanço do pensamento coletivo advindo da Revolução Francesa e os deveres dos cidadãos citados na Declaração de 1795. Em suma, a Constituição é o reflexo dos direitos e deveres entre determinada população e seu Estado, porém como salvaguardar essas premissas sem estabilidade política e territorial?

Propomos a partir deste artigo a análise da evolução acerca do reconhecimento do Estado Palestino, sua organização e constituição, com o intuito de identificar a sua efetividade nos dois territórios: Cisjordânia e Faixa de Gaza, bem como a sua relevância para os atores regionais e internacionais. Pesquisar questões relacionadas ao território palestino não pode ser considerada tarefa fácil. Contudo, a sua importância e característica única nos desafia à compreensão e busca por respostas, dispostas no corpo do artigo. Ressaltamos o caráter temporário deste documento devido às constantes alterações no cenário internacional e esperamos que de alguma forma ele possa contribuir para a reflexão acadêmica.

\section{Desenvolvimento}

\section{Discussões e Resoluções da ONU para "O problema dos Judeus" e "A Questão Palestina"}

Dominado pelo império turco-otomano até o final da Primeira Guerra Mundial, o território palestino esteve sob mandato britânico de

UNITED NATIONS. UN report cites possible war crimes by both Israel and Palestinian groups in 2014 Gaza conflict. Geneva - UN News centre, 2015. Disponível em: <https://goo.gl/NBfqtV. Acesso em: 10/04/2017. 
1922 até 1946, conforme decisão do Conselho da Liga das Nações. A partir do encerramento das atividades da mesma, coube à recém-criada Organização das Nações Unidas promover os debates referentes à independência da Palestina, estabelecendo um comitê ad hoc (UNSCOP) com o intuito de buscar uma solução durável e o mais justa possível, tendo em vista a migração dos judeus para a região, ocupada majoritariamente por muçulmanos.

Realizada a análise, o comitê formado por representantes de Estados Membros da ONU concluiu em agosto de 1947 que o Estado Palestino deveria ser independente após um breve período de transição que deveria ocorrer sob responsabilidade das Nações Unidas, observando os princípios democráticos e respeitando todas as manifestações religiosas dos locais sagrados. Na mesma época, os refugiados judeus pós Segunda Guerra Mundial estavam presentes por toda a Europa, especialmente na Inglaterra, representando uma demanda para o Estado destruído pelos conflitos. Na abertura dos debates, o "problema dos judeus" foi abordado pelos membros da UNSCOP, porém com diferentes propostas. O plano da maioria, composta por Canadá, Checoslováquia, Guatemala, Holanda, Peru, Suécia e Uruguai consistia na divisão da região em dois territórios distintos: Palestina Árabe e Palestina dos Judeus. A economia seria unificada, locais sagrados administrados pela ONU, além de ambos os Estados assumirem o compromisso de elaborar suas respectivas constituições, dentro dos padrões estabelecidos pelos instrumentos internacionais, como requisito para o reconhecimento da soberania.

Por sua vez, a proposta da minoria formada por Índia, Irã e Iugoslávia compreendia a independência de um Estado composto por judeus e árabes, respeitando suas diferenças e prevendo uma constituição única que representasse maioria e minoria. Sobre as duas propostas apresentadas, o Reino Unido emitiu o seguinte parecer:

Seu governo estava pronto para assumir a responsabilidade pela implementação de qualquer plano o qual o acordo fosse alcançado pelos árabes e pelos judeus.

Se, por outro lado, a Assembleia recomendasse uma 
política que não fosse aceitável para ambas as partes, o Governo do Reino Unido não se sentiria apto a implementá-la, e a Assembleia deveria, portanto fornecer, em tal caso, alguma autoridade alternativa para implementá-lo. Especificamente, o Governo do Reino Unido não estava preparado por si só para assumir a tarefa de impor uma política na Palestina pela força das armas. Quanto à possibilidade de a participação de seu governo com outros governos na execução de um acordo, seu governo teria que levar em conta tanto a justiça inerente ao acordo quanto a extensão em que a força seria necessária para sua implementação² (UNITED NATIONS, 1947, p. 212, tradução dos autores).

Cada Estado ou representante discorreu sobre pontos de vista e soluções. Contudo, o consenso não foi alcançado devido às divergências históricas entre árabes e judeus, como entre os atores envolvidos nas negociações. Os árabes palestinos não aceitavam uma divisão por considerarem o território parte de sua cultura e identidade. Morada permanente e impenetrável, invadida por uma campanha migratória intencional e ilegal, consentida pelo Reino Unido durante seu mandato, "em detrimento dos direitos políticos, sociais e econômicos dos Árabes Palestinos" (UNITED NATIONS, 1947, p. 213). Ademais, os representantes árabes palestinos questionaram o não aceite dos judeus às outras propostas realizadas, por exemplo, o fornecimento de uma área em Uganda quarenta anos antes ou Biro-Bdjan (URSS):

2 Do original: His Government was ready to assume responsibility for implementing any plan on which agreement was reached by the Arabs and the Jews. If, on the other hand, the Assembly were to recommend a policy which was not acceptable to both parties, the United Kingdom Government would not feel able to implement it, and the Assembly should therefore provide, in such a case, for some alternative authority implement it. Specifically, the United Kingdom Government was not prepared by itself to undertake the task of imposing a policy in Palestine by force of arms; as to the possibility of his Government's participation with other Governments in the enforcement of a settlement, his Government would have to take into account both the inherent justice of the settlement and the extent to which force would be required for its implementation. 
Recordaram as resoluções pertinentes relativas aos refugiados e deslocados aprovadas pela Assembleia Geral em 12 de fevereiro (8 (I)) 223 e 15 de dezembro (62 (I)), 2241946 a esse respeito e mencionou a oferta do Reino Unido, feito há mais de 40 anos, para colocar Uganda à disposição dos judeus como um lar nacional e, mais recentemente, os esforços da URSS para criar um lar nacional judaico em Biro-Bidjan. Ambos os lugares tinham mais a oferecer aos judeus do que o pequeno país da Palestina, mas os sionistas recusaram. Os sionistas não queriam a Palestina para a solução permanente do problema judaico nem para o alívio dos judeus em dificuldades; eles queriam poder; eles tinham ambições e projetos políticos na Palestina, estrategicamente importante, e no Oriente Próximo. Então, também, seria ilógico que as Nações Unidas se associassem à introdução de um corpo alienígena na homogeneidade estabelecida do mundo árabe, um processo que só poderia produzir "novos Bálcãs"3 (UNITED NATIONS, 1947, p. 232, tradução dos autores).

No caso do posicionamento do representante dos judeus, é evidente o descompasso entre os atores no que tange à busca por uma solução. Considerando as propostas da minoria e maioria inadequadas, os representantes criticaram o fato de os Estados europeus vislumbrarem a solução do "problema dos judeus" a partir da migração para a Palestina,

3 Do original: He recalled the relevant resolutions concerning refugees and displaced persons passed by the General Assembly on February 12 (8 (I) 223 and December 15 (62 (I)), 224 1946, in that connection and mentioned the offer of the United Kingdom, made more than 40 years ago, to place Uganda at the disposal of the Jews as a national home, and, more recently, the efforts of the U.S.S.R. to create a Jewish national home in Biro-Bidjan. Both places had more to offer the Jews than the tiny country of Palestine, but the Zionists had turned them down. The Zionists did not want Palestine for the permanent solution of the Jewish problem nor for the relief of the distressed Jews; they wanted power; they had political ambitions and designs on strategically important Palestine and the Near East. Then, too, it would be illogical for the United Nations to associate itself with the introduction of an alien body into the established homogeneity of the Arab world, a process which could only produce a "new Balkans". 
ressaltando que os judeus não deveriam ser obrigados a viver em apenas um território. Com relação às alegações dos árabes palestinos acerca da legitimidade do pleito judeu, não houve concordância pois os mesmos não cogitavam viver nas áreas demarcadas na proposta do Estado único, tampouco dividir ou permitir a administração de Jerusalém pela Palestina Árabe ou uma autoridade internacional no caso de uma divisão em dois Estados. A única solução possível para os judeus seria que a divisão fosse realizada contemplando a região da Galileia Ocidental e Jerusalém.

A votação para a escolha da melhor proposta foi finalizada com o resultado de 33 votos a favor, 13 contra e 10 abstenções referentes ao plano de divisão do território em dois Estados, com destaque para as seguintes condições:

1. O mandato para a Palestina terminará o mais cedo possível, mas, em qualquer caso, o mais tardar em 1 de agosto de 1948 .

2. As forças armadas da potência mandatória devem ser progressivamente retiradas da Palestina, a retirada deve ser concluída o mais rapidamente possível, mas em qualquer caso, o mais tardar em 1 de agosto de 1948. A potência mandatória deve informar a Comissão, com a maior antecedência possível, da sua intenção de terminar o mandato e de evacuar cada área. A Potência mandatória deverá envidar seus melhores esforços para assegurar que uma área situada no território do Estado Judeu, incluindo um porto marítimo e o interior adequado para fornecer instalações para uma imigração substancial, seja evacuada com a maior brevidade possível e, em qualquer caso, o mais tardar em $1^{\circ}$ de fevereiro de 1948. [...] os árabes que residem na área do Estado judeu proposto e os judeus que residem na área do proposto Estado árabe que assinaram uma notificação de intenção de optar pela cidadania do outro Estado serão elegíveis para votar nas eleições para a Assembleia Constituinte daquele Estado, mas não nas eleições para a Assembleia Constituinte do Estado em 
que residem ${ }^{4}$ (UNITED NATIONS, 1947, p. 233, tradução dos autores).

\begin{abstract}
Atuando como uma espécie de "Constituição modelo", os Steps Preparatory to Independence teve como objetivo conduzir os novos Estados aos instrumentos legais necessários, dentro dos padrões ocidentais, para o funcionamento da democracia, mas, após extensas negociações, por qual razão essas resoluções, no total de 29, não foram implementadas? Segundo análise de HATHAWAY (2005, p. 471), aproximadamente 50 mil tratados no âmbito do Direito Internacional foram criados, cobrindo detalhadamente diversos aspectos das relações internacionais, contudo, sem enfraquecer a ação dos Estados que com frequência utilizam métodos próprios:
\end{abstract}

Talvez não surpreenda, portanto, que grande parte do debate público sobre o direito internacional tenha sido polarizado e improdutivo. Os céticos argumentam veementemente que o direito internacional é mera fachada. Defensores frequentemente assumem que os estados cumprem seus compromissos legais internacionais "quase o tempo todo". 5

4 Do original: 1. The Mandate for Palestine shall terminate as soon as possible but in any case not later than 1 August 1948. 2. The armed forces of the mandatory Power shall be progressively withdrawn from Palestine, the withdrawal to be completed as soon as possible but in any case not later than 1 August 1948. The mandatory Power shall advise the Commission, as far in advance as possible, of its intention to terminate the Mandate and to evacuate each area. The mandatory Power shall use its best endeavours to ensure that an area situated in the territory of the Jewish State, including a seaport and hinterland adequate to provide facilities for a substantial immigration, shall be evacuated at the earliest possible date and in any event not later than 1 February 1948. [...] Arabs residing in the area of the proposed Jewish State and Jews residing in the area of the proposed Arab State who have signed a notice of intention to opt for citizenship of the other State shall be eligible to vote in the elections to the Constituent Assembly of that State, but not in the elections to the Constituent Assembly of the State in which they reside.

5 Do original: It is perhaps not surprising, then, that much of the public debate over international law has been polarized and unproductive. Skeptics argue strenuously that international law is mere window dressing. Advocates frequently assume that states abide by their international legal commitments "almost all of the time". 
A autora defende ainda a importância do devido estudo acerca das razões que levam os Estados a aderir aos instrumentos internacionais, o compromisso e respeito aos mesmos no âmbito doméstico, além das consequências aos seus interesses.

A resposta para a permanência da questão palestina pode não estar mais centralizada na divergência religiosa ou histórica, mas no interesse dos Estados que apoiam Israel, por exemplo, os Estados Unidos da América. No cenário interdependente e globalizado, ignorar ou desrespeitar um tratado internacional pode custar menos do que perder oportunidades comerciais ou territoriais:

Consequências colaterais, ao contrário, surgem quando atores nacionais e transnacionais pressupõem suas ações na direção de um Estado, da decisão do Estado de aceitar ou rejeitar regras legais internacionais. As reações desses atores às ações do Estado podem afetar, entre outras coisas, o investimento estrangeiro, doações de ajuda, comércio internacional, apoio político interno e contribuições políticas e, assim, criar incentivos poderosos para os estados se comprometerem e cumprirem os tratados ${ }^{6}$ (HATHAWAY, 2005, p. 471, tradução dos autores).

Enfim, consideramos que as argumentações sobre a divisão e legitimidade do antigo território palestino e Transjordânia contidas no United Nations Year Book 1947-1948 foram pautadas pelos interesses domésticos dos atores primários e secundários a despeito de uma solução durável para o pleito. A cultura e identidade importou até certo ponto e apenas para judeus e palestinos, enquanto grupos de Estados visavam seus objetivos: participação na negociação, corte de gasto (Reino Unido) e promessas comerciais futuras (Estados Unidos-Israel).

6 Do original: Collateral consequences, by contrast, arise when domestic and transnational actors premise their actions toward a state on the state's decision to accept or reject international legal rules. The reactions of these actors to the state's actions can affect, among other things, foreign investment, aid donations, international trade, domestic political support, and political contributions, and hence create powerful incentives for states to commit to and comply with treaties. 
Para iniciar a nossa análise sobre a Constituição Palestina, promovemos brevemente uma discussão a respeito da formação do Estado-Nação e o papel da Constituição nesse processo.

Os tratados de Munster e Osnabruck (1648), elaborados na região de Vestfália no século XVII são conhecidos na História por instituir e consolidar o Estado moderno, ajustando assim a soberania, política independente de determinada sociedade, a coexistência de vários Estados e a igualdade entre eles. Já o constitucionalismo moderno surgiu com as revoluções dos Estados Unidos (1776) e da França (1789), instituindo assim o alicerce de suas normas por meio de uma carta constitutiva do Estado e de sua nação, ou seja, a Constituição tornou-se a representação maior dos deveres e direitos de uma sociedade, bem como, da organização dos poderes e entes públicos que pertencem àquele Estado. Alexandre de Moraes (2013, p. 1) conceitua o Direito Constitucional da seguinte forma:

O Direito Constitucional é um ramo do Direito Público, destacado por ser fundamental à organização e funcionamento do Estado, à articulação dos elementos primários do mesmo e ao estabelecimento das bases da estrutura política.

A constituição política do Estado tem por função estabelecer sua estrutura, a organização de suas instituições e órgãos, o modo de aquisição e limitação do poder, por meio, inclusive, da previsão de diversos direitos e garantias fundamentais.

Mais do que um conjunto de normas fixadas em um papel, consiste em fenômeno de uma sociedade em suas diversas áreas, quais sejam: política, religiosa, econômica, social e cultural. Por ser a expressão de uma sociedade, a Constituição de um país tem em seu escopo os objetivos, os desejos de sua população e a regulamentação do poder do Estado, assim, nem sempre as normas trazidas são de fato cumpridas, mas sim como expectativa de que um dia elas possam ser garantidas. 
O modo pelo qual uma sociedade moderna se expressa para o mundo empírico é por intermédio de sua Constituição, é o meio pelo qual uma população transforma-se em sociedade, tanto interna quanto externamente para outros Estados. Dado o passo que uma Constituição é a representação maior do Estado-nação, torna-se imprescindível o estudo histórico da sociedade para que a compreensão de sua Carta Magna ocorra de fato e não apenas uma mera conjectura dos motivos de tais textos estarem ou não nela introduzidos, conforme esclarecem Gilmar Mendes e Paulo Gonet (2015, p. 83):

A interpretação orientada à aplicação não se torna completa se o intérprete se bastar com a análise sintática do texto. Como as normas tem por vocação própria ordenar a vida social, os fatos que compõe a realidade e lhe desenham feição específica não podem ser relegados no trabalho do jurista. Para se definir o âmbito normativo do preceito constitucional, para se delinearem a extensão e intensidade dos bens, circunstâncias e interesses atingidos pela norma, não se prescinde da consideração de elementos da realidade.

O princípio da autodeterminação dos povos consiste no direito de expressar em seu território normas e princípios próprios, entre eles a Constituição, constituir o governo e seus órgãos, bem como, aos demais Estados, demonstrar que aquela sociedade possui uma organização que rege os princípios e ideais daquela população. Nesse sentido, Norberto Bobbio ensina quanto aos fundamentos do Direito que:

O problema do fundamento de um direito apresenta-se diferentemente conforme se trate de buscar o fundamento de um direito que se tem ou de um direito que se gostaria de ter. No primeiro caso, investigo no ordenamento jurídico positivo, do qual faço parte como titular de direitos e deveres, se há uma norma válida que o reconheça e qual é essa norma; no segundo caso, tentarei buscar boas razões para defender a legitimidade do direito em questão e para convencer o maior número 
possível de pessoas (sobretudo as que detêm o poder direto ou indireto de produzir normas válidas naquele ordenamento) a reconhece-lo ${ }^{7}$ (BOBBIO, 1992, p. 15).

Em analogia ao ensinado citado por Bobbio e no contexto atual da globalização, da valorização do homem e da cultura de paz entre os povos, a existência de uma Constituição para um Estado-Nação é um dos modos para dizer ao mundo que eles são independentes, reconhecem o seu próprio Estado e suas Leis, tendo assim, a autonomia necessária para exercer sua soberania e tentar convencer o maior número de Estados ao redor do globo, acerca do seu reconhecimento como ente soberano daquela sociedade em questão. A Carta da ONU (1945) salvaguarda o direito de autodeterminação, questão analisada pelo autor Paulo Borba Casella:

A Carta da ONU estipula como um dos princípios da organização, no artigo primeiro, parágrafo segundo, o "princípio da igualdade de direito e de autodeterminação dos povos", o que se retorna e detalha, no Capítulo XII da Carta, "sistema internacional de tutela", cujo artigo 76 , letra "b", declara como objetivo básico do sistema de tutela "fomentar o progresso político, econômico, social e educacional dos habitantes dos territórios tutelados e o seu desenvolvimento progressivo para alcançar governo próprio ou independência, como mais convenha as circunstâncias particulares de cada território e de seus habitantes e aos desejos livremente expostos dos povos interessados, e como for previsto, nos termos de cada acordo de tutela (CASELLA, 2010, p. 279).

Observamos, portanto, que a autodeterminação dos povos é uma ação que confere o direito de organização interna sem interferência externa, ou seja, uma ação soberana. No caso da Palestina, a redação da Constituição não resultou no reconhecimento dos Estados sobre a existência do Estado Palestino.

$7{ }^{7}$ BOBBIO, Norberto. A era dos direitos/Norberto Bobbio; tradução de Carlos Nelson Coutinho. Rio de Janeiro: Campus, 1992, p. 15. 


\section{AnÁlise: o AlCANCE da CONSTituição Palestina}

Conforme introdução deste artigo, a partir da década de 90 Israel e Palestina avançaram as discussões sobre a organização da região e possível reconhecimento do Estado palestino, sob observância da comunidade internacional, resultando na criação da Autoridade Nacional Palestina. Após aproximadamente dez anos e com alguma resistência, o então líder Yasser Arafat promulgou, em 2002, a primeira versão da constituição da Palestina, a qual analisaremos a seguir.

Composta por 112 artigos, a constituição da Palestina busca reforçar aspectos organizacionais de um Estado, a exemplo do sistema legislativo, fiscal, funções do presidente e conselho ministerial, conforme o Direito Internacional. Em específico, a mesma possui artigos que refletem uma intenção, não a realidade, como, por exemplo, o Artigo $3^{\circ}$. que indica Jerusalém como capital do Estado Palestino, ${ }^{8}$ informação que conflita com o status determinado nos documentos do governo de Israel, conforme a seguir:

Jerusalém, o coração e a alma do povo judeu, desempenha um papel central na cultura, história e religião judaicas. Desde 1004 a.c quando o rei Davi estabeleceu Jerusalém como a capital da nação judaica, permaneceu uma constante e duradoura presença judaica na cidade. Além disso, a liturgia judaica, a música, a literatura e a poesia estão repletas de referências a Jerusalém, ou "Sião", o nome bíblico da cidade [...] I. A reivindicação judaica a Jerusalém está arraigada em 3.000 anos de história [...] Jerusalém tem estado no centro da consciência judaica por mais de três mil anos, antes mesmo de o rei Davi fazer dela a capital de seu reino em 1004 a.C. Tais eventos bíblicos como a ligação da escada de Isaac e de Jacó têm sido tradicionalmente conectados a Jerusalém. Nenhuma outra cidade desempenhou um papel tão predominante na história, cultura e religião de um

8 Article $3^{\circ}$. Jerusalem is the Capital of Palestine. 
povo quanto Jerusalém para os judeus. 'Jerusalém', ou 'Sião', é mencionado mais de 800 vezes na Bíblia judaica $^{9}$ (ISRAEL MINISTRY OF FOREIGN AFFAIRS, 1999, tradução dos autores).

Como podemos observar, ambos os atores reclamam a mesma área como parte de seu território, herança cultural e religiosa de seu povo. Mais especificadamente, ambos declaram Jerusalém como capital e possuem suas justificativas:

II. A reivindicação judaica de Jerusalém como sua capital é única;

A. Sempre houve um consenso nacional em Israel sobre o status de Jerusalém. Desde a reunificação da cidade em 1967, todos os governos israelenses declararam sua política que unia Jerusalém, a capital eterna de Israel é uma cidade indivisível sob a soberania israelense e que o livre acesso aos lugares sagrados e a liberdade de culto continuarão garantidos aos membros de todos. Fés.

B. Apenas duas vezes Jerusalém serviu como capital nacional - a capital dos Reinos Bíblicos de Israel e da Judéia antes da destruição romana de 70 EC, e a capital do moderno Estado de Israel desde o renascimento do estado judeu em 1948.

C. Ao lado do povo judeu, nenhuma outra nação ou estado que conquistou a soberania política sobre a

9 Do original: Jerusalem, the heart and soul of the Jewish people, plays a central role in Jewish culture, history and religion. Since 1004 B.C.E. when King David established Jerusalem as the capital of the Jewish nation, there has remained a constant and enduring Jewish presence in the city. Moreover, Jewish liturgy, music, literature and poetry are replete with references to Jerusalem, or "Zion", the Biblical name of the city [...] I. The Jewish claim to Jerusalem is rooted in 3,000 years of history [...] A. Jerusalem has been at the center of Jewish consciousness for over three thousand years, even before King David made it the capital of his kingdom in 1004 B.C.E. Such biblical events as the binding of Isaac and Jacob's ladder have traditionally been connected to Jerusalem. No other city has played such a predominant role in the history, culture, and religion of a people as has Jerusalem for the Jews. 'Jerusalem', or 'Zion', is mentioned over 800 times in the Jewish Bible. 
área fez de Jerusalém uma cidade capital. Ambos os impérios árabe e mameluco decidiram governar de Damasco, enquanto o governante otomano residia em Constantinopla. Além disso, nenhum desses impérios chegou a conceder a Jerusalém o status de capital distrital $^{10}$ (ISRAEL MINISTRY OF FOREIGN AFFAIRS, 1999, tradução dos autores).

Ao analisarmos essas disposições, imaginamos: qual Estado está correto em sua afirmação? Aquele que detém o controle do território citado mediante avanço ou o que era maioria no mesmo até a realização de uma campanha migratória de outro grupo para povoar o local?

Retornamos à constituição palestina, do Artigo $11^{\circ}$. ao Artigo $15^{\circ}$. observamos disposições com relação à segurança e liberdades individuais. ${ }^{11}$ Ninguém pode ser preso sem que as devidas disposições legais sejam seguidas, como a informação sobre os motivos da detenção e

10 Do original: II. The Jewish claim to Jerusalem as their capital is unique A. There has always been a national consensus in Israel on the status of Jerusalem. Since the reunification of the city in 1967, all Israeli Governments have declared their policy that united Jerusalem, Israel's eternal capital is one indivisible city under Israeli sovereignty and that free access to holy places and freedom of worship will continue to be guaranteed to members of all faiths. B. Only twice has Jerusalem served as a national capital -- the capital of the Biblical Kingdoms of Israel and Judea before the Roman destruction of 70 C.E., and the capital of the modern State of Israel since the rebirth of the Jewish state in 1948. C. Beside the Jewish people, no other nation or state which gained political sovereignty over the area had ever made Jerusalem a capital city. Both the Arab and Mamluk empires chose to rule from Damascus, while the Ottoman ruler resided in Constantinople. Furthermore, none of these empires even granted Jerusalem the status of district capital.

11 Article $11^{\circ} .1$. Personal freedom is a natural right, and shall be guaranteed and protected. 2. It is unlawful to arrest, search, imprison, restrict the freedom, or prevent the movement of, any person, except by judicial order in accordance with the provisions of law. The law shall specify the period pre-arrest detention. Imprisonment or detention shall only be permitted in places that are subject to laws related to the organization of prisons.

Article $15^{\circ}$. Punishment shall only be imposed upon individuals. Collective punishment is prohibited. Crime and punishment shall only be determined by law. $\mathrm{Pu}-$ nishment shall be imposed only by judicial order, and shall apply only to actions committed after the promulgation of law. 
contratação de um advogado. Ninguém deve ser torturado. Punições coletivas não podem ser realizadas. Nesse ponto estão os pressupostos que nos levaram à escrita deste artigo: Estas disposições de fato possuem validade para o povo palestino em sua totalidade? Se têm, são reconhecidas regionalmente, e, por fim, pela comunidade internacional?

O Artigo 17 trata da inviolabilidade das residências, cabendo compensação da Autoridade Nacional Palestina caso ocorra algum incidente. ${ }^{12}$ Questionamos: Quais foram as compensações realizadas para as famílias que residem na Faixa de Gaza? A dúvida é pertinente. O governo da Faixa de Gaza não responde à Autoridade Nacional Palestina, que criou e promulgou essa constituição, e que comanda apenas a Cisjordânia. Logo, a constituição seria válida apenas para as regiões sob a influência da Autoridade Nacional Palestina ou independe disso?

Segundo AZZOUNI (2010), a ruptura entre a Faixa de Gaza e a Cisjordânia prejudicou as liberdades individuais, especialmente das mulheres de Gaza, devido à mudança de governo:

Além dos efeitos do congelamento da ajuda internacional, Gaza sofreu uma interrupção no fornecimento de eletricidade e água depois que sua usina foi bombardeada por Israel em meados de 2006. As passagens de fronteira de Gaza só foram abertas esporadicamente desde a tomada do Hamas, deixando os moradores com pouco acesso a recursos básicos e prejudicando gravemente a qualidade de vida das mulheres. Os problemas do território foram exacerbados por um ataque militar israelense que começou no final de dezembro de 2008. Deixaram cerca de 1.400 mortos, incluindo muitas mulheres e crianças, e outros milhares de feridos ou desabrigados. [...] tensões políticas em curso entre Fatah e Hamas, juntamente com restrições israelenses

12 Article $17^{\circ}$. Homes shall be inviolable; thus, they shall not be subject to surveillance, entrance or search, except in accordance with a valid judicial order, and in accordance with the provisions of law. Any consequences resulting from violations of this article shall be considered invalid. Individuals who suffer from such violation shall be entitled to fair compensation guaranteed by the Palestinian National Authority. 
e incursões tem seriamente afetado a saúde das mulheres, oportunidades de emprego, acesso à educação e liberdades políticas e civis em todo o território palestino Além de apresentar desafios em no dia a dia das mulheres, esses fatores têm sistematicamente desviado a atenção dos pedidos de igualdade de gênero nos níveis político e social. Não obstante, os ativistas e organizações de direitos das mulheres estão determinados a perseverar em seus esforços para reformar leis e práticas discriminatórias, como muitas vezes ocorreram durante a trêmula história da Palestina. ${ }^{13}$

Logo, podemos observar a discrepância entre as intenções descritas entre a constituição formulada pela Autoridade Nacional Palestina e a realidade dos cidadãos que vivem na Faixa de Gaza. Poderiam estes recorrer às Organizações Internacionais para salvaguardar seus direitos fundamentais? Essa questão nos levou à busca pelos instrumentos internacionais ratificados pela Palestina, resultando em 14 instrumentos entre Tratados e Convenções ratificados, relacionados aos Direitos Humanos e Políticos. Dessa forma, a Palestina pode ser responsabilizada por atos contrários a esses instrumentos, mesmo que não possua o status de Estado, e sim, de observador.

13 Do original: In addition to the effects of the freezing of international aid, Gaza suffered from an interruption in electricity and water supplies after its power plant was bombarded by Israel in mid-2006. Border crossings out of Gaza have only been opened sporadically since the Hamas takeover, leaving residents with little access to basic resources and severely damaging the quality of life for women. The territory's problems were sharply exacerbated by an Israeli military assault that began in late December 2008. It left some 1,400 people dead, including many women and children, and thousands more injured or homeless. [...] Ongoing political tensions between Fatah and Hamas - coupled with Israeli restrictions and incursions-have seriously affected women's health, employment opportunities, access to education, and political and civil liberties throughout the Palestinian territories.12 In addition to presenting challenges in women's day-to-day lives, these factors have consistently drawn attention away from calls for gender equality at the societal and political levels. Nonetheless, women's rights activists and organizations are determined to persevere in their efforts to reform discriminatory laws and practices, as they have many times during Palestine's tremulous history. 
O progresso da organização do território palestino depende, principalmente, da harmonia entre os grupos que compõem o seu governo. Elaborar uma constituição pode ser considerado um importante passo, mas a sua validade exige o cumprimento de suas disposições que atualmente não se assemelham à realidade dos residentes da Faixa de Gaza.

Em 2017, o presidente dos Estados Unidos, Donald Trump, declarou formalmente Jerusalém como a capital de Israel, ignorando o artigo $13^{\circ}$. da Constituição Palestina que declara Jerusalém sua capital. Como justificativa, o mesmo alegou que os presidentes anteriores não tinham coragem de resolver a situação apropriadamente, conforme o discurso realizado durante a assinatura da declaração:

Os presidentes emitiram essas renúncias sob a crença de que atrasar o reconhecimento de Jerusalém promoveria a causa da paz. Alguns dizem que lhes faltou coragem, mas fizeram seus melhores julgamentos ancorados em fatos como os entendiam na época. No entanto, depois de mais de duas décadas de renúncias, não estamos mais perto de um acordo de paz duradouro entre Israel e os palestinos. Seria loucura presumir que repetir a mesma fórmula produziria agora um resultado diferente ou melhor. Portanto, determinei que é hora de reconhecer oficialmente Jerusalém como a capital de Israel. Enquanto os presidentes anteriores fizeram desta uma grande promessa de campanha, eles não conseguiram entregar. Hoje estou entregando. Eu julguei esse curso de ação como sendo do melhor interesse dos Estados Unidos da América e da busca da paz entre Israel e os palestinos. Este é um passo tardio para avançar no processo de paz e trabalhar para um acordo duradouro. Israel é uma nação soberana com o direito, como qualquer outra nação soberana, de determinar seu próprio capital. Reconhecer isso como um fato é uma condição necessária para alcançar a paz ${ }^{14}$ (THE UNITED STA-

14 Do original: Presidents issued these waivers under the belief that delaying the recognition of Jerusalem would advance the cause of peace. Some say they lacked courage, but they made their best judgments based on facts as they understood them at the time. 
TES OF AMERICA, THE WHITE HOUSE, 2017, tradução dos autores).

Imediatamente, a Organização das Nações Unidas evidenciou os riscos da declaração norte-americana para as negociações de paz. Logo depois, a resolução A/72/428, aprovada em 20 de dezembro de 2017 por 128 Estados (apenas nove contrários), versa sobre "Permanência da soberania do povo Palestino no território Palestino ocupado, incluindo o leste de Jerusalém, e da população Árabe no Planalto Sírio de Golan sobre os seus recursos naturais". ${ }^{15}$ Nela, as Nações Unidas convocam os Estados a reafirmar todos os pressupostos adotados desde 1967 sobre a divisão do território, incluindo pedidos para a devolução de regiões da Palestina ocupadas por Israel.

A declaração dos Estados Unidos foi utilizada pelas Nações Unidas para agir mais efetivamente. A expressiva aderência dos Estados à resolução, que engloba aliados dos Estados Unidos, serviu como um fortalecimento do pleito palestino e uma demonstração de reconhecimento dos seus direitos sobre parte de Jerusalém, e das suas fronteiras como um todo.

Nevertheless, the record is in. After more than two decades of waivers, we are no closer to a lasting peace agreement between Israel and the Palestinians. It would be folly to assume that repeating the exact same formula would now produce a different or better result. Therefore, I have determined that it is time to officially recognize Jerusalem as the capital of Israel. While previous presidents have made this a major campaign promise, they failed to deliver. Today, I am delivering. I've judged this course of action to be in the best interests of the United States of America and the pursuit of peace between Israel and the Palestinians. This is a long-overdue step to advance the peace process and to work towards a lasting agreement. Israel is a sovereign nation with the right like every other sovereign nation to determine its own capital. Acknowledging this as a fact is a necessary condition for achieving peace.

15 Do original: Permanent sovereignty of the Palestinian people in the Occupied Palestinian Territory, including East Jerusalem, and of the Arab population in the occupied Syrian Golan over their natural resources. 


\section{Considerações finais}

Com o intuito de identificar os fatores que contribuem para a permanência do status da Palestina, mesmo após as 29 resoluções da Nações Unidas desde 1947, constatamos que a movimentação dos atores primários e secundários envolvidos não reflete a plena intenção de solucionar a questão dentro das atribuições dos órgãos criados para essa finalidade.

Ao estudar os instrumentos internacionais de proteção, consideramos que os mesmos não são suficientes para resolver a questão, principalmente pela falta de um dispositivo de coerção que garanta o seu cumprimento, função atribuída ao Conselho de Segurança, composto por Estados que possuem relações comerciais com Israel, prejudicando a aplicação de sanções. Entretanto, a declaração dos Estados Unidos da América, reconhecendo Jerusalém como capital de Israel, reacendeu as discussões no âmbito da Assembleia Geral das Nações Unidas, resultando num cenário positivo para a Palestina, que teve reconhecidos seus direitos sobre seu território, como definido em 1967, bem como, a parte leste de Jerusalém, por 128 Estados.

O cenário de discriminação mútua entre os judeus e árabes palestinos interrompe a sua comunicação e a possibilidade de entendimento, fator evidenciado nos elementos conflitantes em suas constituições com a intenção de positivar a sua legitimidade.

No caso da constituição palestina, indicamos a sua importância para a formação organizacional do Estado, mas ressaltamos que a instabilidade entre os grupos que governam a Cisjordânia e Faixa de Gaza enfraquece seus pressupostos interna e externamente, impedindo o avanço das negociações de paz com Israel. Desse modo, consideramos a constituição palestina uma intenção, com validade parcial devido ao seu alcance restrito à Cisjordânia.

\section{REFERÊNCIAS}

AZZOUNI, Suheir. Palestinian Authority and Israeli-Occupied Territories. New York - Freedom House, 2010. Disponível em: <https://goo.gl/4EWY9g>. 
Acesso em: 16/04/2017.

BOBBIO, Norberto. A era dos direitos/Norberto Bobbio; tradução de Carlos Nelson Coutinho. Rio de Janeiro: Campus, 1992.

CASELLA. Manual de direito internacional público/Paulo Borba Casella, Hildebrando Accioly e G. E. do Nascimento e Silva, 18. ed. São Paulo: Saraiva, 2010.

HATHAWAY, Oona A. "Between Power and Principle: An Integrated Theory of International Law" (2005). Faculty Scholarship Series. Paper 836.

http://digitalcommons.law.yale.edu/fss_papers/836

ISRAEL MINISTRY OF FOREIGN AFFAIRS. The Status of Jerusalem. Israel, 1999. Disponível em: <https://goo.gl/zjK5LB>. Acesso em: 10/04/2017.

KOH, Harold Hongju. “Why Do Nations Obey International Law?” (1997). Faculty Scholarship Series. Paper 2101. Disponível em: <https:/goo.gl/Vlgngf>. Acesso em: 10/03/2017.

MENDES. Curso de Direito Constitucional/Gilmar Ferreira Mendes e Paulo Gustavo Gonet Branco, 10. ed. rev. e atual. São Paulo: Saraiva, 2015.

MORAES, Alexandre de. Direito Constitucional/Alexandre de Moraes, 29. ed. São Paulo: Atlas, 2013.

PAleStine. The Palestine Basic Law. Palestine, 2002. Disponível em: $<$ http://www.palestinianbasiclaw.org/basic-law/2002-basic-law $>$. Acesso em 06/04/2017.

TERRA. Resoluções adotadas pela ONU no conflito palestino-israelense. São Paulo- Portal Terra. 2011. Disponível em: https: <//goo.gl/r4Ku3w>. Acesso em: 09/04/2017.

UNITED NATIONS. Resolution adopted by the General Assembly on 20 December 2017. Permanent sovereignty of the Palestinian people in the Occupied Palestinian Territory, including East Jerusalem, and of the Arab population in the occupied Syrian Golan over their natural resources. New York: United Nations, 2017. Disponível em: <http:/www.un.org/en/ga/search/view_ doc.asp?symbol=A/RES/72/240>. Acesso em 16/12/2017.

UNITED NATIONS. Yearbook of the United Nations 1947-1948. New York 
- United Nations. 1948. Disponível em: <https://goo.gl/VSpPoH>. Acesso em: 16/04/2017.

\section{SOBRE OS AUTORES}

\section{Rosilandy Carina Candida Lapa}

Mestranda em Direito e Bacharel em Relações Internacionais pela Universidade Católica de Santos. Bolsista de Iniciação Científica do Instituto de Pesquisas Científicas e Tecnológicas - PROIN com o Projeto "Informação do Estado de Origem".

E-mail: roselapa@outlook.com

\section{Raphael Feitosa Fisori}

Possui graduação em Direito pela Universidade Paulista. Extensão em Advocacia Previdenciária pela Faculdade de Direito Damásio de Jesus e Prática no Júri pela Escola Superior de Advocacia. Especialista em Direito Penal e Processual Penal com habilitação para docência no Ensino Superior pela Faculdade de Direito Damásio de Jesus. Mestrando em Direito Internacional na Faculdade Católica de Santos.

E-mail: raphaelfisori@santos.sp.gov.br

Submetido em: 19-9-2017

Aceito em: 23-3-2018 